\title{
Efficacy and safety of coadministration of once-daily indacaterol and glycopyrronium versus indacaterol alone in COPD patients: the GLOW6 study
}

\author{
This article was published in the following Dove Press journal: \\ International Journal of COPD \\ 24 February 2014 \\ Number of times this article has been viewed
}

\author{
Walter Vincken' \\ Joseph Aumann² \\ Hungta Chen ${ }^{3}$ \\ Michelle Henley ${ }^{3}$ \\ Danny McBryan ${ }^{4}$ \\ Pankaj Goyal ${ }^{4}$ \\ 'Respiratory Division, University \\ Hospital, UZ Brussel, Free \\ University of Brussels, Brussels, \\ Belgium; ' ${ }^{2}$ ongartsenpraktijk, \\ Prins Bisschopssingel, Hasselt, \\ Belgium; ${ }^{3}$ Novartis Pharmaceuticals \\ Corporation, East Hanover, NJ, \\ USA; ${ }^{4}$ Novartis Pharma AG, Basel, \\ Switzerland
}

\begin{abstract}
Background: Addition of a second bronchodilator from a different pharmacological class may benefit patients with moderate-to-severe chronic obstructive pulmonary disease (COPD) whose symptoms are insufficiently controlled by bronchodilator monotherapy. GLOW6 evaluated the efficacy and safety of once-daily coadministration of the long-acting $\beta_{2}$-agonist indacaterol (IND) and the long-acting muscarinic antagonist glycopyrronium (GLY) versus IND alone in patients with moderate-to-severe COPD.
\end{abstract}

Materials and methods: In this randomized, double-blind, parallel group, placebo-controlled, 12-week study, patients were randomized 1:1 to IND $150 \mu \mathrm{g}$ and GLY $50 \mu \mathrm{g}$ daily (IND + GLY) or IND $150 \mu \mathrm{g}$ daily and placebo (IND + PBO) (all delivered via separate Breezhaler ${ }^{\circledR}$ devices). The primary objective was to demonstrate the superiority of IND + GLY versus IND + PBO for trough forced expiratory volume in 1 second $\left(\mathrm{FEV}_{1}\right)$ at week 12 . Other end points included trough $\mathrm{FEV}_{1}$ at day $1, \mathrm{FEV}_{1}$ area under the curve from 30 minutes to 4 hours $\left(\mathrm{AUC}_{30 \mathrm{~min}-4 \mathrm{~h}}\right)$, peak $\mathrm{FEV}_{1}$, inspiratory capacity and trough forced vital capacity (FVC) at day 1 and week 12, and transition dyspnea index (TDI) focal score, COPD symptoms, and rescue medication use over 12 weeks.

Results: A total of 449 patients were randomized (IND + GLY, 226; IND + PBO, 223); 94\% completed the study. On day 1 and at week 12, IND + GLY significantly improved trough FEV versus IND + PBO, with treatment differences of $74 \mathrm{~mL}(95 \%$ CI $46-101 \mathrm{~mL})$ and $64 \mathrm{~mL}(95 \%$ CI 28-99 mL), respectively (both $P<0.001$ ). IND + GLY significantly improved postdose peak $\mathrm{FEV}_{1}, \mathrm{FEV}_{1} \mathrm{AUC}_{30 \mathrm{~min}-4 \mathrm{~h}}$, and trough $\mathrm{FVC}$ at day 1 and week 12 versus IND + $\mathrm{PBO}$ (all $P<0.01$ ). TDI focal score and COPD symptoms (percentage of days able to perform usual daily activities and change from baseline in mean daytime respiratory score) were significantly improved with IND + GLY versus IND + PBO $(P<0.05)$. The incidence of adverse events was similar for the two treatment groups.

Conclusion: In patients with moderate-to-severe COPD, once-daily coadministration of IND and GLY provides significant and sustained improvement in bronchodilation versus IND alone from day 1 , with significant improvements in patient-centered outcomes.

Keywords: indacaterol, glycopyrronium, inhalation therapy, bronchodilation, COPD, Breezhaler $^{\mathbb{R}}$

\section{Introduction}

Bronchodilators are central to the pharmacological management of chronic obstructive pulmonary disease (COPD). ${ }^{1}$ Whereas short-acting bronchodilators are used for immediate relief from symptoms, one or more long-acting bronchodilators (long-acting 
$\beta_{2}$-agonists [LABAs] and long-acting muscarinic antagonists [LAMAs]) are recommended for long-term maintenance therapy in patients with moderate-to-very severe COPD. ${ }^{1,2}$ Long-acting bronchodilators include well-established agents, such as the LAMA tiotropium (once-daily [od]) and the LABAs formoterol and salmeterol (both twice-daily [bid]), and the more recently introduced LAMAs glycopyrronium (NVA237; od) $)^{3,4}$ and aclidinium (bid), ${ }^{5-7}$ and the LABA indacaterol (od).

The efficacy and safety of glycopyrronium and indacaterol, given as long-acting bronchodilator monotherapies in patients with moderate-to-severe COPD, has been demonstrated in several Phase III studies. ${ }^{8-14}$ The effect of indacaterol on lung-function outcomes was shown to be superior to twice-daily LABAs ${ }^{11,14,15}$ and comparable to tiotropium. ${ }^{12,16,17}$ Clinical outcomes, such as dyspnea and health status, have also been shown to improve to a significantly greater extent with indacaterol compared with tiotropium. ${ }^{16}$ Glycopyrronium was shown to have a comparable effect to tiotropium on lung function, symptoms, exacerbations, and rescue medication use, with a significantly more rapid onset of action on day 1 compared with tiotropium. ${ }^{13}$ Glycopyrronium has also demonstrated an immediate and significant improvement in exercise tolerance over 3 weeks compared with placebo, beginning with the first dose; this was accompanied by sustained reductions in lung hyperinflation. ${ }^{8}$

In patients whose symptoms are insufficiently controlled by bronchodilator monotherapy, the Global initiative for chronic Obstructive Lung Disease (GOLD) strategy for the management of COPD recommends the addition of a second bronchodilator $^{1}$; this is supported by evidence showing that the addition of a second bronchodilator from a different pharmacological class improves lung function, symptoms, and health status compared with monotherapy, without significantly increasing the risk of side effects. ${ }^{18-20}$

Several studies have established the superior efficacy of free combinations of LABAs and LAMAs in bronchodilation, symptom control, and rescue medication use versus the LAMA monocomponent ${ }^{21-25}$ and versus the LABA monocomponent. ${ }^{18,20,26}$ Recently, INTRUST-1 and INTRUST-2 study investigators reported that concurrent administration of a LABA (indacaterol) and a LAMA (tiotropium) provided superior bronchodilation and lung deflation compared with LAMA (tiotropium) monotherapy. ${ }^{21}$ Furthermore, QVA149, a once-daily, fixed-dose combination of glycopyrronium $50 \mu \mathrm{g}$ and indacaterol $150 \mu \mathrm{g}$ (in development), has demonstrated superior efficacy compared with both monocomponents in a recent study. ${ }^{27}$
In the present GLOW6 (GLycopyrronium bromide in COPD airWays clinical study 6), we aimed to evaluate the efficacy and safety of the coadministration of a LABA (indacaterol $150 \mu \mathrm{g}$ od) and a LAMA (glycopyrronium $50 \mu \mathrm{g}$ od) versus the LABA (indacaterol $150 \mu \mathrm{g}$ od) alone in patients with moderate-to-severe COPD.

\section{Materials and methods Patients}

The GLOW6 study enrolled men and women $\geq 40$ years of age, with moderate-to-severe stable COPD (GOLD stage II or III according to the 2010 GOLD guidelines), ${ }^{28}$ who were current or ex-smokers with a smoking history of at least 10 pack-years, and had a post-bronchodilator forced expiratory volume in 1 second $\left(\mathrm{FEV}_{1}\right) \geq 30 \%$ and $<80 \%$ of the predicted normal and postbronchodilator $\mathrm{FEV}_{1} /$ forced vital capacity (FVC) ratio of $<0.70$ at screening (GOLD stage II or III). ${ }^{28}$ Postbronchodilator refers to 1 hour after sequential inhalation of $84 \mu \mathrm{g}$ ipratropium bromide (or equivalent dose) and $400 \mu \mathrm{g}$ salbutamol (or equivalent dose).

The main exclusion criteria included respiratory tract infection within 6 weeks prior to screening; COPD exacerbation requiring treatment with antibiotics and/or oral corticosteroids and/or hospitalization 6 weeks prior to screening; concomitant pulmonary disease (such as lung fibrosis, sarcoidosis, interstitial lung disease, pulmonary hypertension, clinically significant bronchiectasis, pulmonary tuberculosis); history of asthma, diabetes (with the exception of controlled type II diabetes), malignancy of any organ system, long QT syndrome or QTc $>450 \mathrm{~ms}$ at screening, symptomatic prostatic hyperplasia, bladderneck obstruction, moderate/severe renal impairment, urinary retention, narrow-angle glaucoma, a known history of $\alpha_{1}$-antitrypsin deficiency, or paroxysmal atrial fibrillation; clinically significant renal, cardiovascular (such as, but not limited to, unstable ischemic heart disease, New York Heart Association class III/IV left ventricular failure, myocardial infarction), neurological, immunological, psychiatric, gastrointestinal, hepatic, or hematological abnormality that could have interfered with the assessment of efficacy and safety of the study treatment; participation in the active phase of a supervised pulmonary rehabilitation program; and contraindications for tiotropium or ipratropium, or history of adverse reactions to inhaled anticholinergics.

All patients gave written, informed consent to participate in the study (NCT01604278). ${ }^{29}$ The study protocol was reviewed and approved by institutional review boards and 
ethics committees at participating centers. The study was conducted in compliance with Good Clinical Practice (GCP). Table S1 lists the study centers.

\section{Study design and treatment}

GLOW6 was a multicenter, randomized, double-blind, parallelgroup, placebo-controlled, 12-week study. After a washout period (up to 7 days), followed by a 14-day run-in period, patients were randomized 1:1 to indacaterol $150 \mu \mathrm{g}$ od and glycopyrronium $50 \mu \mathrm{g}$ od (IND + GLY; $50 \mu \mathrm{g}$ refers to the quantity of the glycopyrronium moiety present in the capsule, which corresponds to a delivered dose of $44 \mu \mathrm{g}$ ) or indacaterol $150 \mu \mathrm{g}$ od and placebo (IND + PBO). All treatments were delivered via separate Breezhaler ${ }^{\circledR}$ (Novartis, Basel, Switzerland) devices, and were taken each morning between 8 and 11 (Figure 1). The devices were not to be used interchangeably by the patients, and alternative inhalation devices were not permitted.

An automated, interactive, voice-response technology was used to assign randomization numbers to patients who met the study criteria. Randomization numbers were used to link patients to treatment groups and these were not communicated to the caller. Patients, investigators, site staff, persons performing the assessments and data analysts were blind to the identity of the treatment from the time of randomization. Randomization data were kept strictly confidential until the time of unblinding.

Patients were to discontinue taking long-acting bronchodilator therapy before starting the run-in period (for at least 7 days for LAMAs and the LABA indacaterol, and for 48 hours for other LABAs or LABA/inhaled corticosteroid
[ICS] combinations). Those on fixed-dose LABA/ICS combinations were switched to ICS monotherapy at a dose equivalent to that contained in the fixed-dose combination. Patients were provided with a salbutamol (short-acting $\beta_{2}$-agonist) inhaler to be used as rescue medication during the study. They were instructed to abstain from taking rescue medication within 6 hours of the start of each study visit. Further details are provided in Table S2.

\section{Efficacy assessments}

The primary efficacy variable was trough $\mathrm{FEV}_{1}$ (defined as the mean of the 23 hour 15 minute and 23 hour 45 minute postdose values, imputed with last observation carried forward) at week 12. Secondary variables included trough $\mathrm{FEV}_{1}$ at day $1, \mathrm{FEV}_{1}$ area under the curve from 30 minutes to 4 hours $\left(\mathrm{AUC}_{30 \mathrm{~min}-4 \mathrm{~h}}\right.$ ), peak $\mathrm{FEV}_{1}, \mathrm{FEV}_{1}$ and inspiratory capacity (IC) at individual time points, trough FVC at day 1 and week 12, transition dyspnea index (TDI) focal score, COPD symptoms collected via patient diaries, and mean change from baseline in daily number of puffs of rescue medication over the 12-week treatment period. Effects on the St George's Respiratory Questionnaire - COPD (SGRQ-C) total score at week 12 versus baseline were assessed as an exploratory objective.

Spirometric measurements (recorded via centralized spirometry) were taken prior to the run-in period to determine study eligibility and to record postbronchodilator $\mathrm{FEV}_{1}$ 1 hour after sequential inhalation of four $21 \mu \mathrm{g}$ puffs of ipratropium bromide (or equivalent dose) and four $100 \mu \mathrm{g}$ puffs of salbutamol. $\mathrm{FEV}_{1}$ and $\mathrm{FVC}$ were recorded at all clinic visits

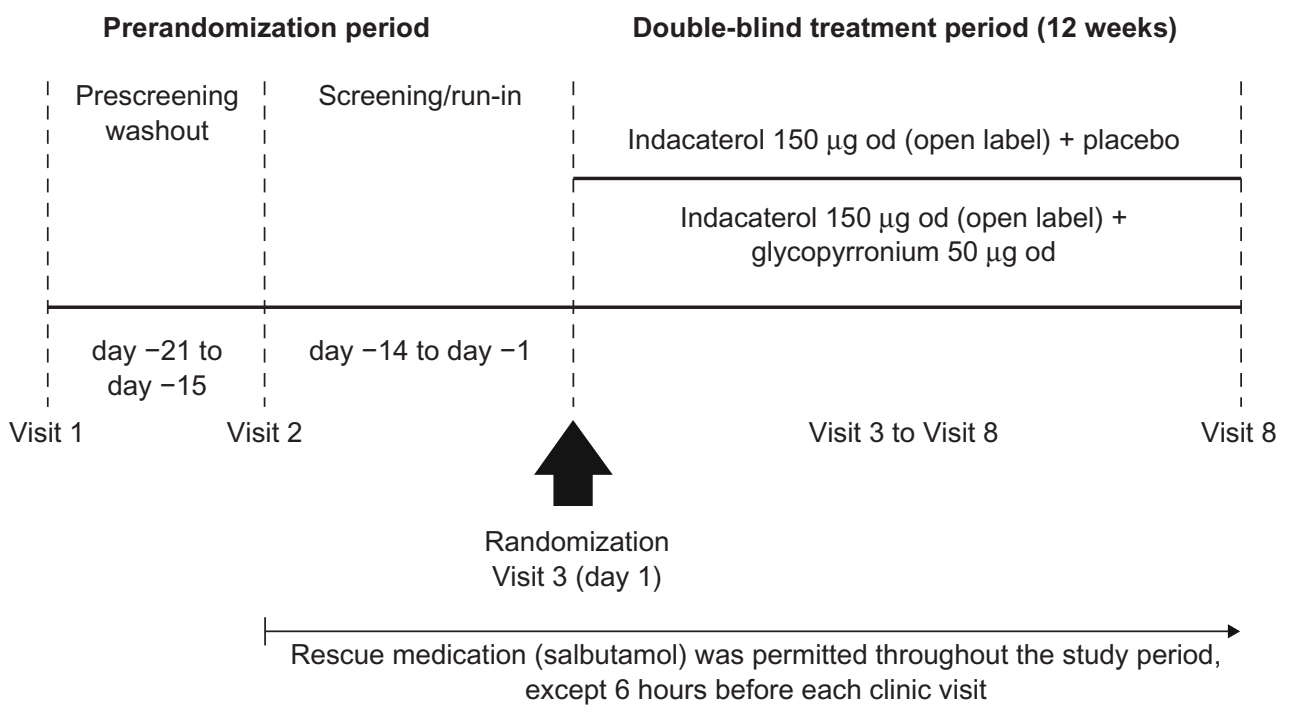

Figure I GLOW6 study design. Abbreviation: od, once-daily. 
at the following time points relative to the morning dose: 45 and 15 minutes predose, and 30 minutes, 1 hour, 4 hours, and 24 hours postdose on day 1 and week 12. Dyspnea was assessed by an investigator-administered baseline dyspnea index and TDI, and health status by self-administered SGRQ-C at day 1 and week 12.

All patients were provided with an eDiary to record morning and evening daily clinical symptoms: cough, wheezing, shortness of breath, sputum volume, sputum purulence, cold, fever, sore throat, nighttime awakenings and rescue medication use, and time of study-drug administration. Patients were instructed to complete the eDiary routinely at the same time each morning (prior to taking the study drug) and again (approximately 12 hours later) each evening, considering events over the previous 12 hours. Patient diaries were reviewed at each clinic visit.

\section{Safety assessments}

Safety was assessed by recording all treatment-emergent adverse events (AEs) and serious AEs (SAEs), monitoring vital signs (pulse rate and systolic and diastolic blood pressure), and performing laboratory analyses (hematology, clinical chemistry, and urinalysis). AEs starting on or after the time of first inhalation of the study drug but not later than 7 days (30 days in the case of SAEs) after last inhalation of the study drug were classified as treatment-emergent AEs. AEs were coded using the Medical Dictionary for Regulatory Activities ${ }^{30}$ and summarized by primary system organ class, preferred term, maximum severity, and relationship to study drug. An independent adjudication committee classified the reported serious cardio- and cerebro-vascular (CCV) events.

\section{Statistical analysis}

Three populations were defined in the GLOW6 study for the purpose of analysis. The full analysis set (FAS) included all randomized patients who received at least one dose of the study drug; patients were analyzed according to the treatment they were assigned to at randomization. The per-protocol set (PPS) included all patients in the FAS who had no major protocol deviations; patients were analyzed according to the treatment to which they were randomized. The safety population included all patients who received at least one dose of the study medication, irrespective of randomization; patients were analyzed according to the treatment they received.

The primary analysis for trough $\mathrm{FEV}_{1}$ at week 12 was performed on the FAS using a mixed model. The mixed model contained treatment as a fixed effect, with the baseline
$\mathrm{FEV}_{1}$ and $\mathrm{FEV}_{1}$ prior to and post inhalation of short-acting bronchodilator as covariates. The model also included smoking status at baseline (current/ex-smoker), history of baseline ICS use (yes/no) and region as fixed effects, and center (nested in the region) as a random effect. If any of the values contributing to trough $\mathrm{FEV}_{1}$ were collected within 6 hours of rescue medication or within 7 days of systemic corticosteroid use, then the individual $\mathrm{FEV}_{1}$ value was not included in the analysis. Superiority of IND + GLY versus IND + PBO was claimed if the difference in trough $\mathrm{FEV}_{1}$ was statistically significant at the 5\% level and the $95 \%$ confidence interval (CI) was entirely to the right of (higher than) $0.0 \mathrm{~L}$.

Other secondary variables were analyzed in the FAS using the same mixed model as the primary analysis, with the respective baseline values replacing baseline $\mathrm{FEV}_{1}$ as a covariate. Results are shown as least squares means (LSMs) with standard errors for group mean values and with $95 \%$ CIs for differences between treatments. The procedure for handling missing data is detailed in Table S3.

Additionally, exploratory subgroup analyses were performed for the primary end point to explore the treatment effect by age ( $<65$ and $\geq 65$ years), sex (male/female), smoking history (ex-smokers/current smokers), severity of disease, use of ICS at baseline (yes/no) and body mass index $\left(\mathrm{BMI} ;>30 \mathrm{~kg} / \mathrm{m}^{2}\right.$ or $\left.\leq 30 \mathrm{~kg} / \mathrm{m}^{2}\right)$ in the FAS. The analysis was performed with the appropriate interaction term in the model and the additional covariate as a fixed effect, if necessary. All safety end points were summarized for the safety population.

\section{Sample-size calculation}

To detect statistical significance in the primary end point (at $\alpha=0.05$, with $80 \%$ power) for a treatment differential of $70 \mathrm{~mL}$ in trough $\mathrm{FEV}_{1}$ at week 12, and assuming a standard deviation of $250 \mathrm{~mL}$ and a $10 \%$ dropout rate, it was calculated that an estimated total sample size of 450 patients (225 per group) would be required (404 completers).

\section{Results}

\section{Patient disposition and baseline characteristics}

A total of 671 patients were screened, of whom 449 were randomized (IND + GLY, 226; IND + PBO, 223; Figure 2); 94\% (422 patients) completed the study. The percentage of patients who discontinued was similar in both groups. The two most common reasons for discontinuing treatment were protocol deviation and AEs. Discontinuations were more frequent due to protocol deviation in the IND + GLY 


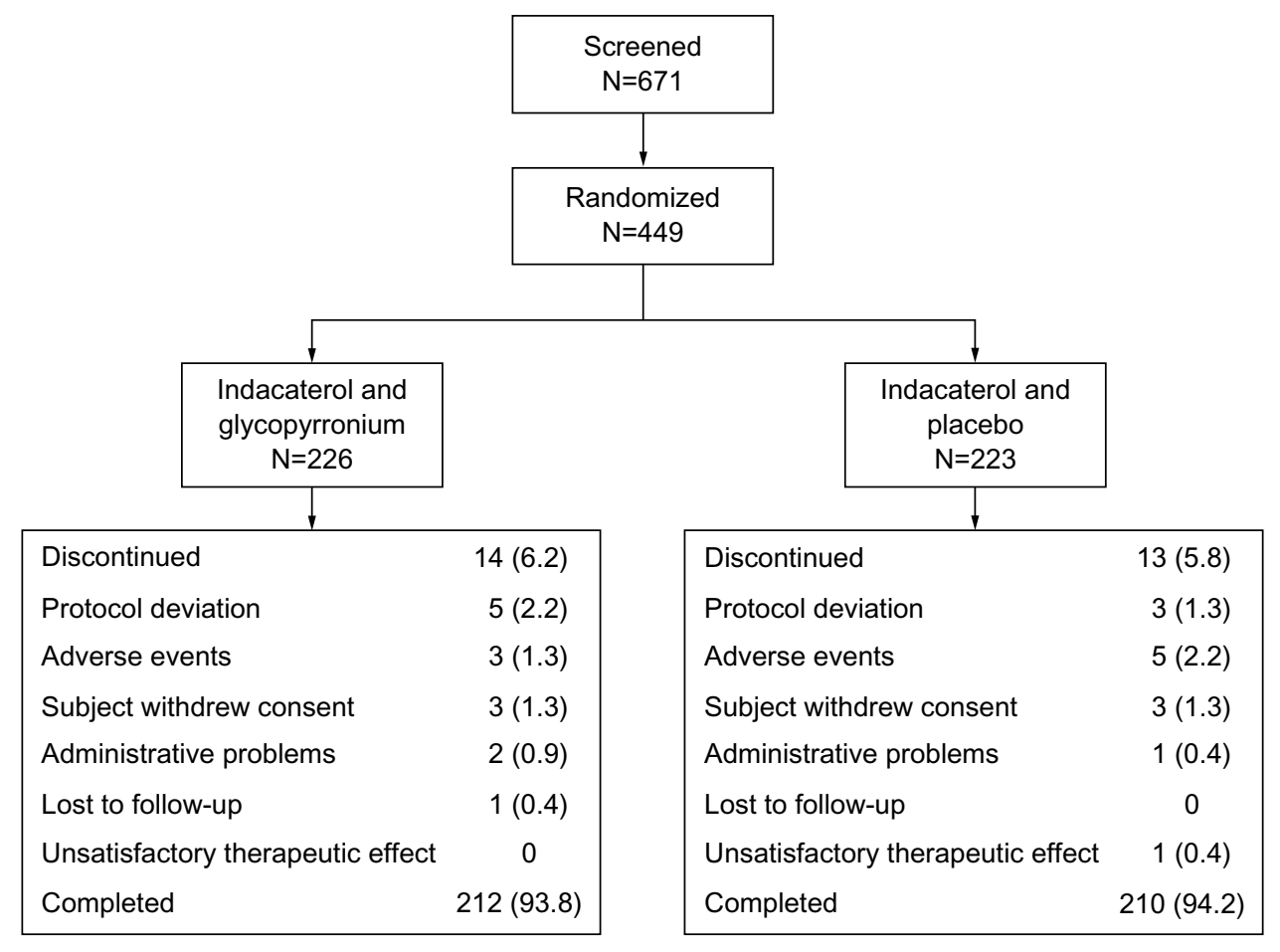

Figure 2 Patient disposition, n (\%).

group (five of 14 patients; $2.2 \%$ ) than in the IND + PBO group (three of 13 patients; $1.3 \%$ ); they were more frequent due to AEs in the IND + PBO group (five of 13 patients; $2.2 \%$ ) than in the IND + GLY group (three of 14 patients; $1.3 \%$ ).

All baseline characteristics were similar between the treatment groups (Table 1). The mean age of the patients was 63.7 years, $82 \%$ of the patients were male and the majority (99\%) were Caucasian. All patients had moderate (64\%) or severe (36\%) airflow limitation. ${ }^{1}$ All patients were smokers (42\%) or ex-smokers $(58 \%)$, and the mean smoking history was 44.5 pack-years. The mean duration of COPD was 7.1 years; $30 \%$ of the patients had a documented history of at least one exacerbation in the previous year; $63 \%$ of the patients used ICS. Mean postbronchodilator $\mathrm{FEV}_{1}$ was $54.8 \%$ predicted, and mean postbronchodilator $\mathrm{FEV}_{1} / \mathrm{FVC}$ ratio was $48.5 \%$.

\section{Efficacy}

\section{Spirometry}

The primary end point in GLOW6 was met, as the LSM trough $\mathrm{FEV}_{1}$ at week 12 was significantly higher in the IND + GLY group than in the IND + PBO group, with a treatment difference of $64 \mathrm{~mL}$ (95\% CI 28-99 mL, $P<0.001$; Table 2 and Figure 3). Similar results were seen in the supportive analysis in the PPS, with a treatment difference of $64 \mathrm{~mL}$ (95\% CI 28-101 mL, $P<0.001)$. After first dose, the treatment difference for trough $\mathrm{FEV}_{1}$ (measured at the end of day 1 as the mean of the values at 23 hours 15 minutes and 23 hours 45 minutes) was $74 \mathrm{~mL}(95 \%$ CI $46-101 \mathrm{~mL}, P<0.001)$ in favor of IND + GLY versus IND + PBO (Table 2 and Figure 3). IND + GLY was also statistically significantly superior to IND $+\mathrm{PBO}$ for $\mathrm{FEV}_{1} \mathrm{AUC}_{30 \min -4 \mathrm{~h}}$ postdose and peak $\mathrm{FEV}_{1}$ on day 1 and at week 12 (all $P<0.001$, Table 2).

On day 1 and at week $12, \mathrm{FEV}_{1}$ at all time points from 30 minutes to 4 hours and at 24 hours was significantly higher in the IND + GLY group compared with the IND + PBO group, with statistically significant treatment differences at each time point (all $P<0.001$ [except at 24 hours on week $12 P<0.01$ ], Figure 4 ).

Trough FVC on day 1 and at week 12 was significantly higher in the IND + GLY treatment group than in the IND + PBO group (LSM treatment differences, $111 \mathrm{~mL}[P<0.001]$ and $93 \mathrm{~mL}[P=0.006]$, respectively; Table 2 ). IC at 2 hours and 4 hours postdose on day 1 and at 30 minutes, 2 hours, and 4 hours postdose at week 12 was significantly higher in the ING + GLY treatment group compared with the IND + PBO treatment group (Table 2).

The exploratory subgroup analyses of trough $\mathrm{FEV}_{1}$ at week 12 demonstrated superiority of IND + GLY versus IND + PBO for most subgroups evaluated, consistent with the result for trough $\mathrm{FEV}_{1}$ in the overall FAS; younger patients ( $<65$ years), patients with severe airflow limitation, ${ }^{1}$ ICS users at baseline, and current smokers in the IND + GLY treatment group had a 
Table I Baseline demographics, background characteristics, and spirometry (safety population)

\begin{tabular}{|c|c|c|}
\hline & $\begin{array}{l}\text { IND + GLY } \\
(\mathbf{N}=\mathbf{2 2 6})\end{array}$ & $\begin{array}{l}\text { IND + PBO } \\
(\mathrm{N}=\mathbf{2 2} 1)\end{array}$ \\
\hline Mean (SD) age, years & $63.4(8.44)$ & $64.1(7.67)$ \\
\hline Male, n (\%) & $180(79.6)$ & $186(84.2)$ \\
\hline \multicolumn{3}{|l|}{ Ethnicity, n (\%) } \\
\hline Caucasian & $224(99.1)$ & $217(98.2)$ \\
\hline Native American & 0 & $\mathrm{I}(0.5)$ \\
\hline Other & $2(0.9)$ & $3(1.4)$ \\
\hline \multirow{2}{*}{\multicolumn{3}{|c|}{$\begin{array}{l}\text { Severity of airflow limitation } \\
\text { (GOLD 20I3), } \mathrm{n}(\%)\end{array}$}} \\
\hline & & \\
\hline Moderate & $139(6 \mid .5)$ & $148(67.0)$ \\
\hline Severe & $87(38.5)$ & $73(33.0)$ \\
\hline Mean $(S D)$ duration of COPD, years & $7.1(5.65)$ & $7.2(5.35)$ \\
\hline \multicolumn{3}{|l|}{ Baseline COPD exacerbation } \\
\hline \multicolumn{3}{|l|}{ history, ${ }^{*}$ (\%) } \\
\hline 0 exacerbations & $158(69.9)$ & $156(70.6)$ \\
\hline I exacerbation & $57(25.2)$ & $46(20.8)$ \\
\hline$\geq 2$ exacerbations & II (4.9) & $19(8.6)$ \\
\hline ICS use at baseline, $\mathrm{n}(\%)$ & $138(6||)$. & $142(64.3)$ \\
\hline \multicolumn{3}{|l|}{ Smoking history, n (\%) } \\
\hline Ex-smoker & $130(57.5)$ & $129(58.4)$ \\
\hline Current smoker & $96(42.5)$ & $92(41.6)$ \\
\hline $\begin{array}{l}\text { Mean (SD) duration of smoking, } \\
\text { pack-years }\end{array}$ & $44.5(23.40)$ & $44.4(22.24)$ \\
\hline Mean (SD) FEV, postbronchodilator, L & $1.5(0.46)$ & $1.6(0.46)$ \\
\hline Mean (SD) postbronchodilator & $54.2(12.90)$ & $55.5(12.62)$ \\
\hline \multicolumn{3}{|l|}{$\mathrm{FEV}, \%$ predicted } \\
\hline Mean (SD) postbronchodilator & $19.4(\mid 4.82)$ & $19.6(|4.7|)$ \\
\hline \multicolumn{3}{|l|}{$\mathrm{FEV}$, reversibility, \% } \\
\hline Mean (SD) postbronchodilator & $48.8(9.83)$ & $48.1(|0.2|)$ \\
\hline $\mathrm{FEV}_{1} / \mathrm{FVC}, \%$ & & \\
\hline
\end{tabular}

Notes: *In the year prior to screening; duration of COPD calculated from the date first diagnosed with COPD until visit I; pack-years = total years of smoking multiplied by cigarette packs smoked per day.

Abbreviations: COPD, chronic obstructive pulmonary disease; $\mathrm{FEV}_{1}$, forced expiratory volume in I second; FVC, forced vital capacity; GLY, glycopyrronium; GOLD, Global initiative for chronic Obstructive Lung Disease; ICS, inhaled corticosteroids; IND, indacaterol; PBO, placebo; SD, standard deviation.

significantly higher improvement in trough $\mathrm{FEV}_{1}$ at week 12 versus patients in the IND + PBO group (Figure 5).

\section{Symptoms, diary-card data, health status}

TDI focal score at week 12 showed a greater reduction in dyspnea with IND + GLY than with IND + PBO, with an LSM difference of 0.49 units ( $95 \%$ CI $0.03-0.96$ units, $P=0.037$; Table 2 and Figure 6). Patients receiving IND + GLY were significantly more likely to achieve a minimum clinically important improvement (MCID; $\geq 1$ unit improvement) in dyspnea ${ }^{31}$ than those taking IND + PBO (76.6\% versus $62.2 \%$, respectively; odds ratio [OR] 1.97, 95\% CI 1.24-3.11; $P=0.004)$.

Over the 12-week treatment period, diary-card data showed a significant improvement in the percentage of days
Table 2 Differences between treatments for primary and secondary efficacy outcomes on day I and at week 12 (FAS)

\begin{tabular}{|c|c|c|}
\hline Variable & $\begin{array}{l}\text { LSM }(95 \% \mathrm{Cl}) \text { treatment } \\
\text { difference (IND + GLY } \\
\text { vs IND + PBO) }\end{array}$ & $P$-value \\
\hline \multicolumn{3}{|l|}{ Day I } \\
\hline Trough FEV, $\mathrm{L}$ & $0.074(0.046-0.101)$ & $<0.001$ \\
\hline Peak FEV, L & $0.108(0.079-0.137)$ & $<0.001$ \\
\hline $\mathrm{FEV}_{1} \mathrm{AUC}_{30 \mathrm{~min}-4 \mathrm{~h}}, \mathrm{~L}$ & $0.106(0.080-0.132)$ & $<0.001$ \\
\hline Trough FVC, L & $0.111(0.054-0.167)$ & $<0.001$ \\
\hline IC at 30 min postdose, $\mathrm{L}$ & $0.059(-0.001-0.118)$ & 0.054 \\
\hline $\mathrm{IC}$ at $2 \mathrm{~h}$ postdose, $\mathrm{L}$ & $0.109(0.039-0.179)$ & 0.003 \\
\hline IC at $4 \mathrm{~h}$ postdose, $\mathrm{L}$ & $0.083(0.014-0.152)$ & 0.019 \\
\hline \multicolumn{3}{|l|}{ Week I2 } \\
\hline $\begin{array}{l}\text { Trough } \mathrm{FEV}_{1}, \mathrm{~L} \\
\text { (primary end point) }\end{array}$ & $0.064(0.028-0.099)$ & $<0.001$ \\
\hline Trough FEV , in the PPS, L & $0.064(0.028-0.101)$ & $<0.001$ \\
\hline Peak FEV ${ }_{1}, \mathrm{~L}$ & $0.106(0.070-0.143)$ & $<0.001$ \\
\hline $\mathrm{FEV}_{1} \mathrm{AUC}_{30 \mathrm{~min}-4 \mathrm{~h}}, \mathrm{~L}$ & $0.111(0.076-0.145)$ & $<0.001$ \\
\hline Trough FVC, L & $0.093(0.027-0.160)$ & 0.006 \\
\hline IC at 25 min predose, L & $0.081(0.002-0.160)$ & 0.043 \\
\hline IC at 30 min postdose, $\mathrm{L}$ & $0.159(0.073-0.246)$ & $<0.001$ \\
\hline $\mathrm{IC}$ at $2 \mathrm{~h}$ postdose, $\mathrm{L}$ & $0.122(0.037-0.207)$ & 0.005 \\
\hline IC at $4 \mathrm{~h}$ postdose, $\mathrm{L}$ & $0.138(0.05 \mathrm{I}-0.225)$ & 0.002 \\
\hline IC at $24 \mathrm{~h}$ postdose, $\mathrm{L}$ & $0.068(-0.014-0.150)$ & 0.105 \\
\hline TDI focal score & $0.494(0.030-0.958)$ & 0.037 \\
\hline SGRQ-C total score & $-1.47(-3.42-0.48)$ & 0.140 \\
\hline \multicolumn{3}{|l|}{ Over 12 weeks } \\
\hline \multicolumn{3}{|l|}{ Rescue-medication use } \\
\hline $\begin{array}{l}\text { Change from baseline in mean } \\
\text { daily number of puffs }\end{array}$ & $-0.1(-0.5-0.2)$ & $0.47 \mathrm{I}$ \\
\hline $\begin{array}{l}\text { Percentage of days with } \\
\text { no rescue-medication use }\end{array}$ & $0.2(-6.0-6.5)$ & 0.945 \\
\hline $\begin{array}{l}\text { Change from baseline in mean } \\
\text { daily total symptom score }\end{array}$ & $0.0(-0.3-0.3)$ & 0.810 \\
\hline $\begin{array}{l}\text { Change from baseline } \\
\text { in mean daytime respiratory } \\
\text { symptom score }\end{array}$ & $-0.1(-0.1-0.0)$ & 0.025 \\
\hline $\begin{array}{l}\text { Percentage of days able } \\
\text { to perform usual activities }\end{array}$ & $6.2(1.2-11.3)$ & 0.016 \\
\hline
\end{tabular}

Note: Results of analysis in the FAS, unless otherwise stated.

Abbreviations: AUC, area under the curve; $\mathrm{Cl}$, confidence interval; $\mathrm{FAS}$, full analysis

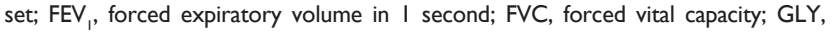
glycopyrronium $50 \mu \mathrm{g}$; IC, inspiratory capacity; IND, indacaterol $150 \mu \mathrm{g}$; LSM, least squares mean; PBO, placebo; PPS, per protocol set; SGRQ-C, St George's Respiratory Questionnaire - COPD; TDI, transition dyspnea index; vs, versus; COPD, chronic obstructive pulmonary disease.

able to perform usual activities in patients receiving IND + GLY, compared with patients receiving IND + PBO (LSM difference $6.2 \%, P=0.016$; Table 2). Significant differences were also observed in change from baseline in mean daytime respiratory symptom score with IND + GLY versus IND + PBO (LSM difference $-0.1,95 \%$ CI $-0.1-0.0 ; P=0.025$; Table 2).

No significant differences were seen between the two treatment groups in the change from baseline in mean daily 


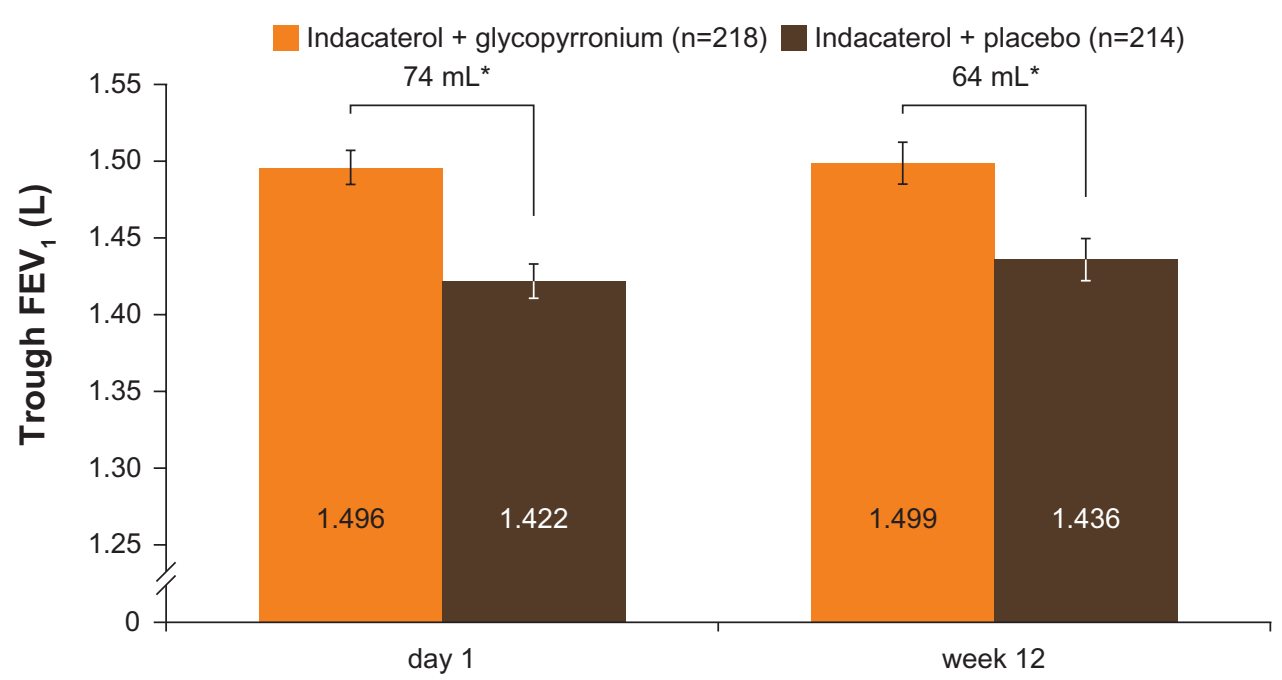

Figure 3 Trough FEV, after first dose (end of day I) and week 12 (FAS).

Notes: $* P<0.001$. Data are least squares means \pm standard error.

Abbreviations: FAS, full analysis set; $\mathrm{FEV}_{1}$, forced expiratory volume in I second.

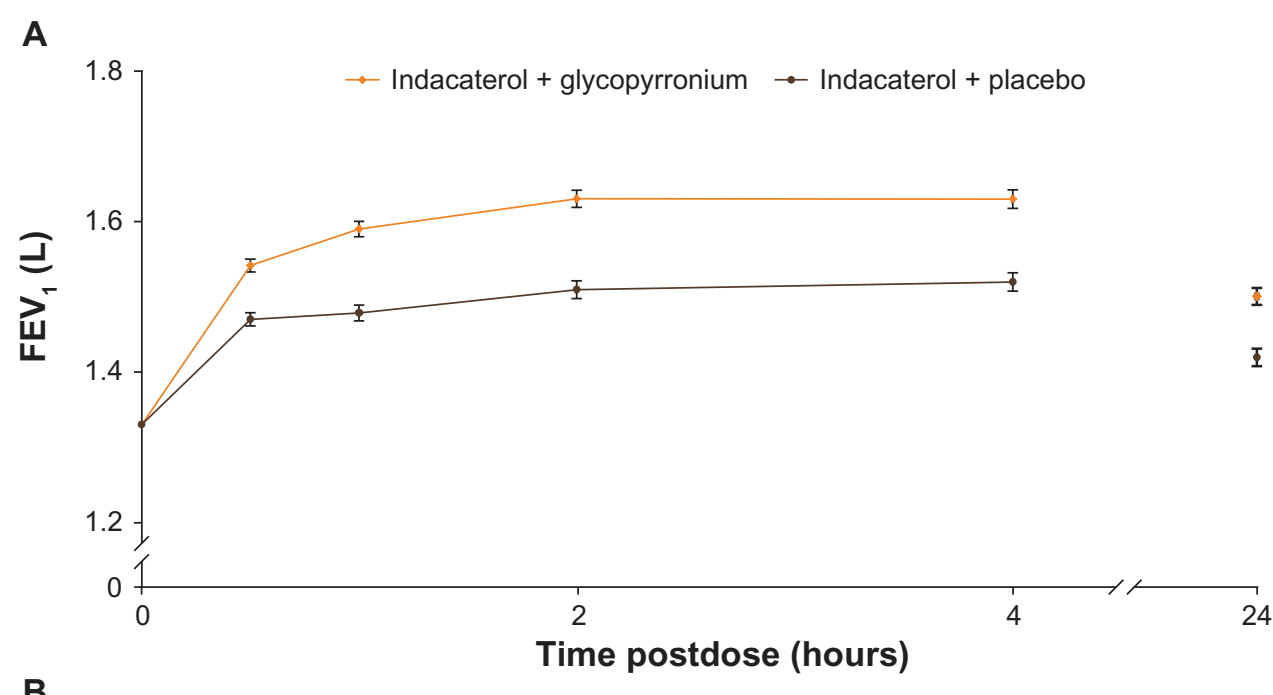

B

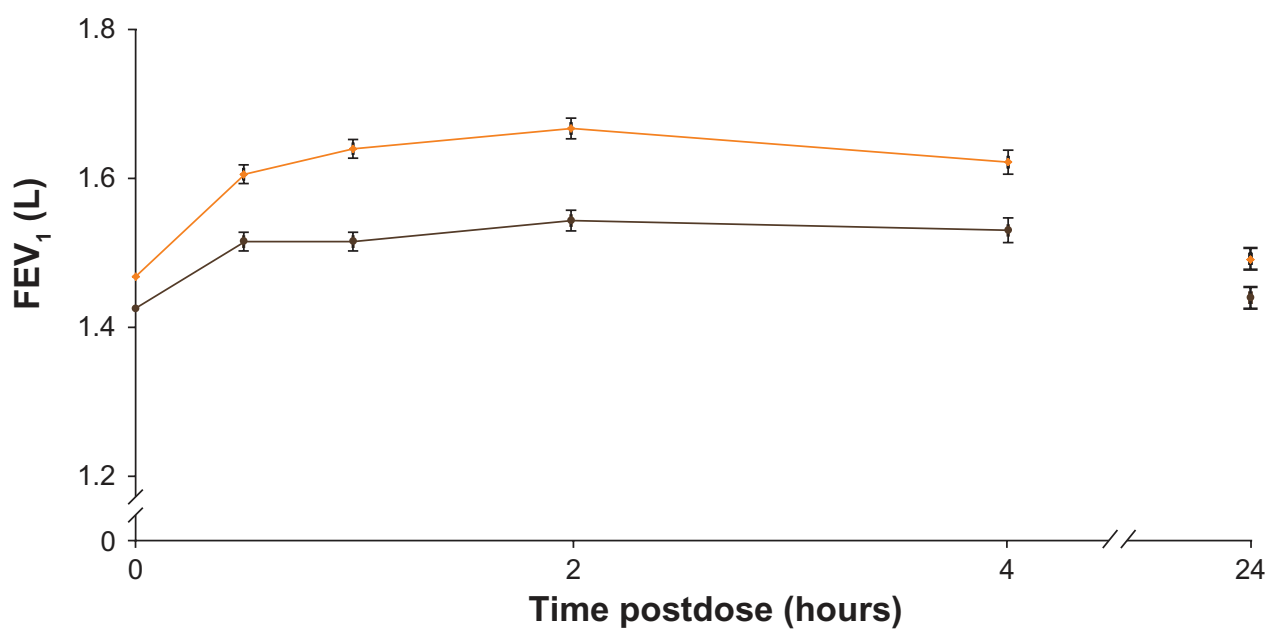

Figure $4 \mathrm{FEV}$, from 30 minutes to 4 hours postdose and 24 hours postdose (A) on day I and (B) at week I2 (FAS).

Notes: $P<0.00 \mathrm{I}$ at all time points from 30 minutes to 4 hours and at 24 hours, except at 24 hours on week 12 where $P<0.01$. Data are least-squares means \pm standard error. Abbreviations: $\mathrm{FEV}_{1}$, forced expiratory volume in I second; FAS, full analysis set. 


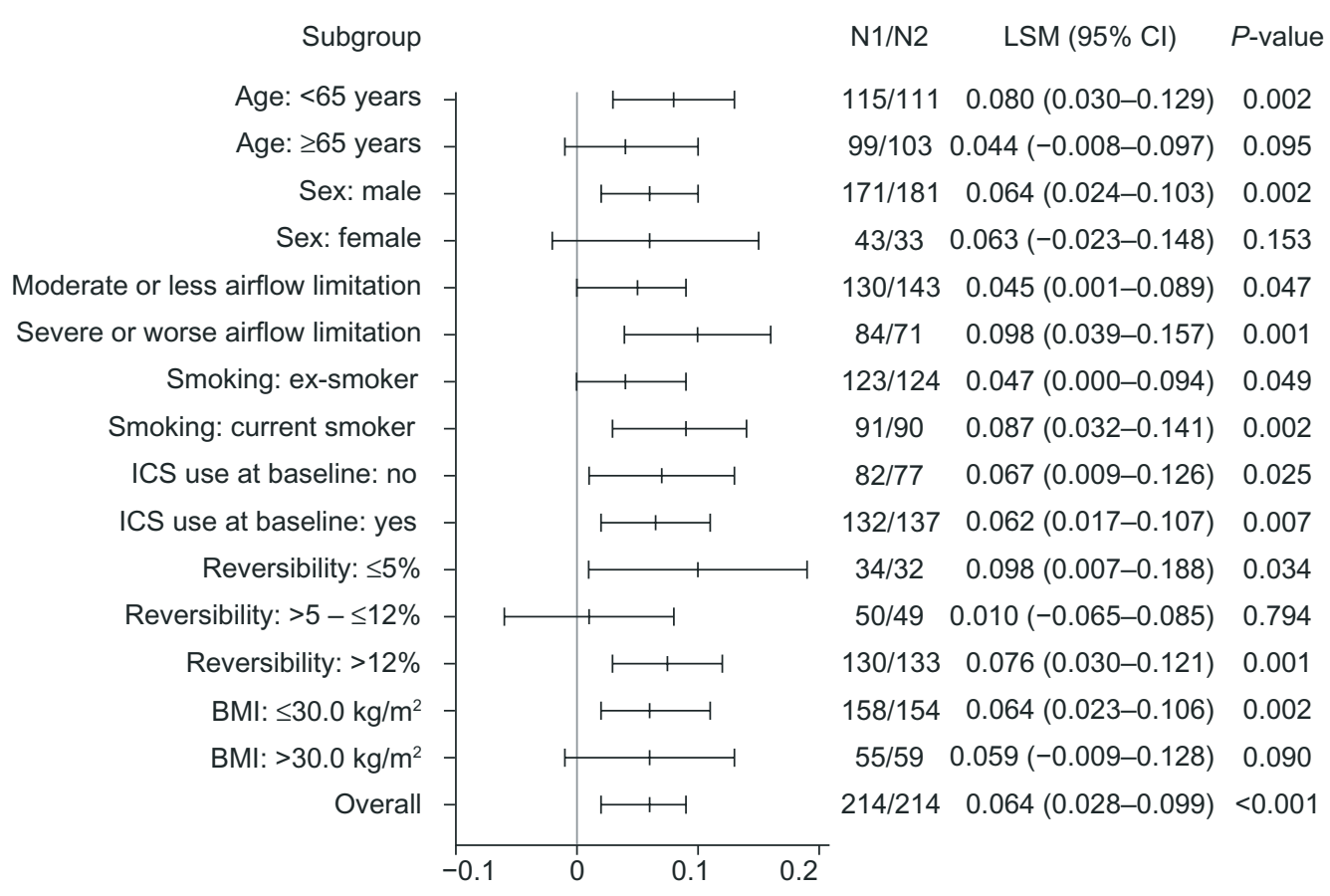

Estimated treatment differences (L) and $95 \% \mathrm{CI}$

Figure 5 Subgroup analyses of treatment differences in trough FEV, at week 12 (FAS).

Note: Data are least squares mean $\pm 95 \% \mathrm{Cl}$.

Abbreviations: BMI, body mass index; Cl, confidence interval; FAS, full analysis set; FEV , forced expiratory volume in I second; ICS, inhaled corticosteroid; LSM, least squares mean; NI, number of patients analyzed in the indacaterol + glycopyrronium treatment group; N2, number of patients analyzed in the indacaterol + placebo treatment group.

number of puffs of rescue medication (treatment difference $-0.1,95 \% \mathrm{CI}-0.5-0.2 ; P=0.471)$, in the percentage of days with no rescue medication use (treatment difference 0.2 , 95\% CI $-6.0-6.5 ; P=0.945$ ), or in the change from baseline in mean daily total symptom score (treatment difference $0.0,95 \% \mathrm{CI}-0.3-0.3 ; P=0.810$ ) over the 12 -week treatment period (Table 2).

In the exploratory assessment of health status, there was a numerical difference in the SGRQ-C total score between IND + GLY versus IND + PBO at week 12; the LSM treatment difference was -1.47 points $(95 \% \mathrm{CI}-3.42-0.48$ points;

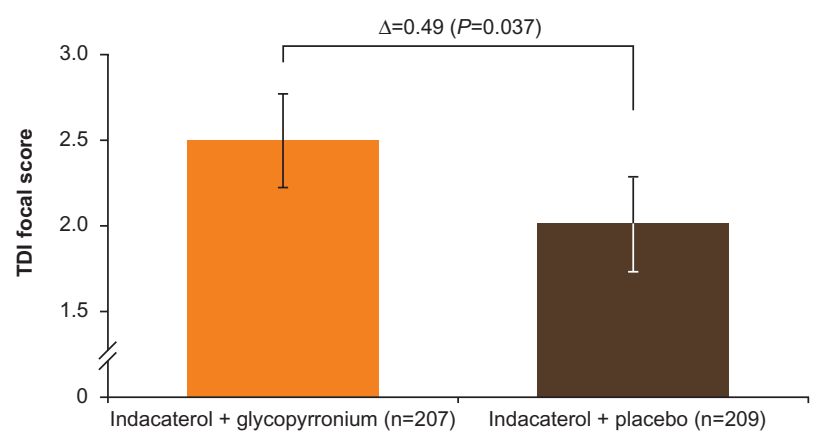

Figure 6 TDI focal score at week 12 (FAS).

Note: Data are least squares means \pm standard error

Abbreviations: FAS, full analysis set; TDI, transition dyspnea index.
$P=0.140$; Table 2). Raw mean (standard deviation) changes (improvements) from baseline were -6.22 (11.47) and -4.13 (10.38) with IND + GLY and IND + PBO, respectively. A higher percentage of patients taking IND + GLY achieved an MCID in SGRQ-C score ( $\geq 4$-point reduction) versus patients taking IND + PBO, but the difference was not statistically significant ( $56.5 \%$ versus $46.8 \%$, respectively; OR $1.4395 \%$ CI $0.95-2.17 ; P=0.089) .{ }^{32}$

\section{Safety}

The overall incidence of AEs was similar between the two treatment groups (IND + GLY 37.6\%, IND + PBO 33.9\%; Table 3). The most frequently reported AE was COPD worsening, seen with similar frequency in both treatment groups (Table 3). Other frequently occurring AEs (at least three patients in either treatment group) included nasopharyngitis, lower respiratory tract infection, cough, back pain, upper respiratory tract infection and oropharyngeal pain. Lower respiratory tract infection occurred with higher frequency in the IND + GLY group, while the frequency of cough was higher in the IND + PBO group (Table 3). AEs leading to discontinuation occurred in a comparable number of patients in both groups (Table 3 ).

SAEs occurred with similar frequency in both treatment groups (Table 4). The proportion of patients with newly 
Table 3 Most frequent AEs (at least three patients in either treatment group) and discontinuations due to AEs (safety population), n (\%)

\begin{tabular}{|c|c|c|}
\hline Preferred term & $\begin{array}{l}\text { IND + GLY } \\
(\mathrm{N}=226), \mathrm{n}(\%)\end{array}$ & $\begin{array}{l}\text { IND + PBO } \\
(\mathrm{N}=22 \mathrm{I}), \mathrm{n}(\%)\end{array}$ \\
\hline Any $\mathrm{AE}(\mathrm{s})$ & $85(37.6)$ & $75(33.9)$ \\
\hline COPD worsening* & $33(14.6)$ & $28(12.7)$ \\
\hline Nasopharyngitis & $10(4.4)$ & II (5.0) \\
\hline Lower respiratory tract infection & $7(3.1)$ & $2(0.9)$ \\
\hline Cough & $6(2.7)$ & $10(4.5)$ \\
\hline Back pain & $4(1.8)$ & $3(1.4)$ \\
\hline Upper respiratory tract infection & $4(1.8)$ & $5(2.3)$ \\
\hline Bacterial infection & $3(1.3)$ & 0 \\
\hline Headache & $3(1.3)$ & $2(0.9)$ \\
\hline Influenza & $3(1.3)$ & $\mathrm{I}(0.5)$ \\
\hline Pain in extremity & $3(1.3)$ & $\mathrm{I}(0.5)$ \\
\hline $\begin{array}{l}\text { Upper respiratory tract } \\
\text { infection, bacterial }\end{array}$ & $3(1.3)$ & $4(1.8)$ \\
\hline $\begin{array}{l}\text { Viral upper respiratory } \\
\text { tract infection }\end{array}$ & $3(1.3)$ & $5(2.3)$ \\
\hline Oropharyngeal pain & 0 & $5(2.3)$ \\
\hline $\begin{array}{l}\text { Discontinuation from study } \\
\text { drug due to } A E(s)\end{array}$ & $3(1.3)$ & $4(1.8)$ \\
\hline
\end{tabular}

Note: *Including COPD exacerbations.

Abbreviations: AE, adverse event; GLY, glycopyrronium $50 \mu \mathrm{g} ; \mathrm{IND}$, indacaterol $150 \mu \mathrm{g} ; \mathrm{PBO}$, placebo; COPD, chronic obstructive pulmonary disease.

occurring or worsening clinically notable QT interval with Fridericia's correction (QTcF) values was similar in the IND + PBO group (3.8\%) and the IND + GLY group (2.8\%). The percentage of patients with an increase in QTcF of $30-60 \mathrm{~ms}$ from baseline was slightly higher in the IND + GLY group (6.5\%) than in the IND + PBO group (4.2\%). The incidence of CCV events was low in both groups: $1.3 \%$ patients in the IND + GLY group and $2.3 \%$ patients in the IND + PBO group. Only angina pectoris was experienced by more than one patient in either treatment group; two patients in the IND + PBO group reported these events, and only one of these events was classified as serious. No deaths were reported in the study.

\section{Discussion}

In the GLOW6 study, once-daily coadministration of IND + GLY provided significantly greater improvement in trough $\mathrm{FEV}_{1}$ on day 1 and at week 12 versus indacaterol alone, with treatment differences of $74 \mathrm{~mL}$ and $64 \mathrm{~mL}$, respectively $(P<0.001)$. Peak $\mathrm{FEV}_{1}$ and $\mathrm{FEV}_{1} \mathrm{AUC}_{30 \mathrm{~min}-4 \mathrm{~h}}$ at day 1 and week 12 were also significantly superior with IND + GLY versus indacaterol alone. Coadministration of IND + GLY also provided statistically significant improvements in dyspnea $(P=0.037)$ and COPD symptoms (percentage of days able to perform usual activities $[P=0.026]$ and change from baseline in mean daytime respiratory symptom score $[P=0.025])$
Table 4 SAEs (safety population), $\mathrm{n}(\%)$

\begin{tabular}{lll}
\hline $\begin{array}{l}\text { Primary system organ class } \\
\text { Preferred term }\end{array}$ & $\begin{array}{l}\text { IND + GLY } \\
(\mathbf{N}=\mathbf{2 2 6}), \mathbf{n} \text { (\%) }\end{array}$ & $\begin{array}{l}\text { IND + PBO } \\
\mathbf{( N = 2 2 ~ I ) , ~} \mathbf{n}(\%)\end{array}$ \\
\hline Patients with any SAE(s) & $5(2.2)$ & $5(2.3)$ \\
Respiratory, thoracic and & $2(0.9)$ & $2(0.9)$ \\
mediastinal disorders & & \\
COPD worsening* & $\mathrm{I}(0.4)$ & $2(0.9)$ \\
Hemoptysis & $\mathrm{I}(0.4)$ & 0 \\
Gastrointestinal disorders & $\mathrm{I}(0.4)$ & 0 \\
Inguinal hernia & $\mathrm{I}(0.4)$ & 0 \\
Immune system disorders & $\mathrm{I}(0.4)$ & 0 \\
Hypersensitivity & $\mathrm{I}(0.4)$ & 0 \\
Infections and infestations & $\mathrm{I}(0.4)$ & $\mathrm{I}(0.5)$ \\
Bacterial infection & $\mathrm{I}(0.4)$ & 0 \\
Urinary tract infection & 0 & $\mathrm{I}(0.5)$ \\
Musculoskeletal and connective & $\mathrm{I}(0.4)$ & 0 \\
tissue disorders & & \\
Osteitis & $\mathrm{I}(0.4)$ & 0 \\
Cardiac disorders & 0 & $\mathrm{I}(0.5)$ \\
Angina pectoris & 0 & $\mathrm{I}(0.5)$ \\
Injury, poisoning, and & 0 & $\mathrm{I}(0.5)$ \\
procedural complications & & $\mathrm{I}(0.5)$ \\
Rib fracture & 0 & $\mathrm{I}(0.5)$ \\
Renal and urinary disorders & 0 & $\mathrm{I}(0.5)$ \\
Renal failure, acute & 0 &
\end{tabular}

Notes: *Including COPD exacerbations; a patient with multiple occurrences of an SAE was counted only once in the SAE category.

Abbreviations: COPD, chronic obstructive pulmonary disease; GLY, glycopyrronium $50 \mu \mathrm{g}$; IND, indacaterol I50 $\mu$; PBO, placebo; SAE, serious adverse event.

over the 12-week treatment period versus monotherapy. Both treatments had an acceptable safety profile.

In the 2013 GOLD strategy document, the free combination of a LABA plus LAMA is a recommended treatment option for all patients except those with the mildest severity of the disease. ${ }^{1}$ The additional benefit provided by combining bronchodilators from different pharmacological classes is a recognized phenomenon. This has been demonstrated in studies combining two short-acting agents ${ }^{33,34}$ and also in studies investigating the combination of the LAMA tiotropium and twice-daily LABAs. ${ }^{18,20,25,26}$ More recently, the additional benefits of combining a once-daily LAMA with a once-daily LABA has been explored, and the results have demonstrated superior efficacy versus the respective monotherapies. . $^{21,27,35}$

Results from the present GLOW6 study support these findings and also the GOLD recommendation. The treatment difference of $64 \mathrm{~mL}$ in trough $\mathrm{FEV}_{1}$ between IND + GLY versus IND + PBO observed at week 12 in the GLOW6 study was consistent with results from the SHINE study, where treatment with QVA149 (a fixed-dose combination of glycopyrronium and indacaterol in Phase III development) resulted in a treatment difference of $70 \mathrm{~mL}$ in trough $\mathrm{FEV}_{1}$ 
$(P<0.001)$ versus indacaterol at week $26 .{ }^{27}$ The magnitude of improvement in trough $\mathrm{FEV}_{1}$ at week 12 in the present study was also comparable to that reported in the INTRUST- 1 and INTRUST-2 studies, where differences of $80 \mathrm{~mL}$ and $70 \mathrm{~mL}$, respectively (both $P<0.001$ ), were observed with indacaterol plus tiotropium versus tiotropium plus placebo. ${ }^{21}$

In GLOW6, coadministration of IND + GLY demonstrated a greater improvement in $\mathrm{FEV}_{1} \mathrm{AUC}_{30 \mathrm{~min}-4 \mathrm{~h}}$ compared with indacaterol alone on day $1(106 \mathrm{~mL})$ and at week 12 (111 $\mathrm{mL})$. Furthermore, $\mathrm{FEV}_{1}$ at all time points from 30 minutes to 4 hours and at 24 hours on day 1 and at week 12 was significantly higher with IND + GLY versus indacaterol. These results indicate an early onset and sustained 24-hour bronchodilation with the coadministration of the two oncedaily long-acting bronchodilators; this may have particular relevance for patients who struggle to undertake morning activities due to COPD symptoms. ${ }^{36}$ It is noteworthy that in the GLOW2 study, which evaluated glycopyrronium $50 \mu \mathrm{g}$ od versus open-label tiotropium $18 \mu \mathrm{g}$ od, $\mathrm{FEV}_{1} \mathrm{AUC}_{0-4 \mathrm{~h}}$ was significantly higher with glycopyrronium versus tiotropium on day 1 (treatment difference $56 \mathrm{~mL}, P<0.001$ ) and at week 26 (treatment difference $50 \mathrm{~mL} ; P<0.01$ ). ${ }^{13}$ Thus, the coadministration of IND + GLY appears to provide an additional improvement in $\mathrm{FEV}_{1} \mathrm{AUC}_{0-4 \mathrm{~h}}$. This improvement in $\mathrm{FEV}_{1} \mathrm{AUC}_{30 \mathrm{~min}-4 \mathrm{~h}}$ at week 12 with the coadministration in the GLOW6 study was similar in magnitude to that seen in the SHINE study, where a treatment difference of $110 \mathrm{~mL}$ was observed in $\mathrm{FEV}_{1} \mathrm{AUC}_{0-4 \mathrm{~h}}$ between QVA149 and indacaterol at week $26(P<0.001) .{ }^{27}$ Furthermore, in GLOW6, the significantly greater improvement in IC observed with the coadministration of IND + GLY at almost all assessed time points on day 1 (except $30 \mathrm{~min}$ post dose) and at week 12 (except predose trough IC, ie 24 hours postdose) compared with indacaterol monotherapy indicates a superior reduction in hyperinflation.

In the present study, coadministration of IND + GLY also significantly improved dyspnea (measured by TDI) compared with indacaterol alone (treatment difference 0.49 units, $P=0.037$ ), suggesting that the coadministration results in additional improvement in dyspnea compared with monotherapy. Although the MCID of $\geq 1$-unit improvement in TDI score is widely applied in COPD trials for comparisons versus placebo as well as between active treatments, it is not actually validated for comparison between different active treatments, only against placebo. ${ }^{31}$ Indacaterol has been shown to achieve the MCID in TDI focal score versus placebo, ${ }^{11,12}$ as well as active treatment (tiotropium), ${ }^{12,16}$ and in GLOW6, the improvement in TDI focal score seen with coadministration of IND + GLY is an incremental benefit over indacaterol alone. Also, it is noteworthy that in the BLAZE study, QVA149 provided a clinically meaningful improvement in TDI focal score versus placebo (treatment difference 1.37 units, $P<0.001$ ), while the mean improvement over tiotropium was 0.49 units $(P=0.021) .{ }^{35}$

The percentage of patients in the current study who achieved a clinically meaningful improvement in dyspnea ( $\geq 1$-unit improvement) was significantly higher in the IND + GLY treatment group than in the IND + PBO group $(76.3 \%$ and $62.2 \%$, respectively). In addition to the improvement in dyspnea, coadministration of IND + GLY also significantly improved patient-reported COPD symptoms versus indacaterol alone (the percentage of days able to perform usual activities and the change from baseline in mean daytime respiratory symptom score over 12 weeks), indicating better symptom control when using two long-acting bronchodilators from different classes.

Although the exploratory assessment of health status did not demonstrate a statistically significant difference between the two treatments, a numerical improvement was observed with the coadministration of IND + GLY versus indacaterol alone. The study duration of the GLOW6 study (12 weeks) might have impacted on this evaluation, and a longer-term study might potentially be able to demonstrate a greater and more significant separation between the two treatments for this end point. Studies of 6-12 months' duration are proposed as the optimal length to capture data on patient-reported outcomes. ${ }^{36}$

Overall, the results of the subgroup analyses were consistent with those of the overall analyses, and demonstrated the benefit of coadministration of two long-acting bronchodilators over monotherapy. Results of the subgroup analysis also provided an indication of the patient groups who could potentially derive immediate, greater benefit from the coadministration of IND + GLY compared with indacaterol alone, ie, patients with severe or worse airflow limitation, younger patients ( $<65$ years), ICS users, and patients who are current smokers. However, it is not known whether these trends for the subgroups are maintained over the longer term.

The safety profile of the coadministration of IND + GLY was acceptable. A small imbalance was observed in the cardiac disorders AEs (IND + GLY, two patients [0.9\%]; IND $+\mathrm{PBO}$, seven patients [3.2\%]), but was not considered clinically meaningful. This could potentially be attributed to the aging COPD population, and also to the multiple comorbidities that are usually prevalent in patients with COPD. ${ }^{37}$

The study duration of GLOW6 was 12 weeks, which may be too short a period of time to detect improvements 
in outcomes for chronic diseases such as COPD, especially symptomatic end points. This could be a reason why significant separation was not seen on all secondary end points. Further, $63 \%$ of the patients in the study were on baseline ICS, and these patients continued on a stable daily dose of ICS throughout the study, which may have impacted on the magnitude of the treatment effects observed. Our study population did not enroll patients with all severities of COPD who may benefit from coadministration of two long-acting bronchodilators. It has been shown that it is patients with moderate COPD who show the greatest improvements in lung function, ${ }^{38,39}$ and the primary aim of our study was to assess the additional benefit in lung function from the coadministration of two long-acting bronchodilators versus one.

For the pharmacological management of COPD, longacting bronchodilators given once-daily have been shown to be superior to short-acting bronchodilators and are also preferred. ${ }^{1,40}$ As demonstrated by the current study, once-daily combination therapy with a LABA plus a LAMA provides further benefits over LABA monotherapy, providing superior bronchodilation and symptom relief, with an acceptable safety profile. Hence, in COPD patients who are insufficiently controlled by long-acting bronchodilator monotherapy, a step up to long-acting bronchodilator combination therapy appears to be an effective and safe next step, potentially preferable over therapy with a combination of a LABA plus an ICS. Indeed, in non-frequent exacerbators, combination therapy with the fixed-dose, dual-bronchodilator QVA149 was more efficacious in terms of improvement in pulmonary function and symptom relief versus combination therapy with a LABA plus an ICS, ${ }^{41}$ at the same time avoiding safety issues (such as pneumonia) encountered in COPD patients treated with $\mathrm{ICS}^{42}$

\section{Conclusion}

The results from the GLOW6 study demonstrate that in patients with moderate-to-severe COPD, coadministration of indacaterol $150 \mu \mathrm{g}$ od and glycopyrronium $50 \mu \mathrm{g}$ od via the Breezhaler $^{\circledR}$ device was safe and well tolerated and provided a rapid onset of effect on day 1 and significant and sustained improvements in bronchodilation along with reduction in symptoms over 12 weeks, compared with indacaterol $150 \mu \mathrm{g}$ od, demonstrating the benefits of adding a second long-acting bronchodilator for the treatment of patients with COPD.

\section{Author contributions}

All authors read and approved the final manuscript. WV was the principal investigator of this multicenter study, reviewed the clinical study report and manuscript drafts, and discussed and cowrote the final manuscript. JA was an investigator in the study, reviewed and revised the manuscript drafts at all stages, and approved the final draft. $\mathrm{HC}, \mathrm{MH}, \mathrm{DMcB}$, and $\mathrm{PG}$, as employees of the sponsor, contributed to the design, preparation, conduct, analysis, and interpretation of the study.

\section{Acknowledgments}

The study was sponsored by Novartis Pharma AG. The authors were assisted in the preparation of the manuscript by Shilpa Mudgal, a professional medical writer contracted to CircleScience (Macclesfield, UK), and Mark J Fedele (Novartis). The authors would also like to thank Damon Jack (Novartis) for his contribution to the study conduct and manuscript preparation. Writing support was funded by the study sponsor. ClinicalTrials.gov identifier: NCT01604278.

\section{Disclosure}

WV has acted as consultant for Boehringer Ingelheim/Pfizer, GlaxoSmithKline, AstraZeneca, Meda Pharmaceuticals, Chiesi, Mundipharma, Novartis, and MSD. JA has no conflicts of interest. $\mathrm{HC}, \mathrm{MH}, \mathrm{DMcB}$, and $\mathrm{PG}$ are employees of the study sponsor and have no other conflicts to declare.

\section{References}

1. Global Strategy for the Diagnosis, Management and Prevention of COPD, Global Initiative for Chronic Obstructive Lung Disease (GOLD) 2013. Available from: http://www.goldcopd.org/. Accessed on January 8, 2014.

2. Cazzola M, Matera MG. Long-acting bronchodilators are the first-choice option for the treatment of stable COPD. Chest. 2004;125(1):9-11.

3. European Medicines Agency (EMA). Seebri Breezhaler (glycopyrronium bromide: summary of product characteristics. Available from: http:// www.ema.europa.eu/docs/en_GB/document_library/EPAR_-_Product_ Information/human/002430/WC500133769.pdf. Accessed June 25, 2013.

4. Novartis Global. Novartis receives European Commission approval for once-daily Seebri ${ }^{\circledR}$ Breezhaler ${ }^{\circledR}$ as maintenance COPD treatment in the EU [press release]. Basel, Switzerland: Novartis; 2012 [October 1]. Available from: http://www.novartis.com/newsroom/media-releases/ en/2012/1645116.shtml. Accessed 22 November, 2012.

5. European Medicines Agency (EMA). Bretaris Genuair (aclidinium bromide): summary of product characteristics. Available from: http:// www.ema.europa.eu/docs/en_GB/document_library/EPAR_-_Product_ Information/human/002706/WC500132732.pdf. Accessed June 25, 2013.

6. European Medicines Agency (EMA). Eklira Genuair (aclidinium bromide): summary of product characteristics. Available from: http:// www.ema.europa.eu/docs/en_GB/document_library/EPAR_-_Product_ Information/human/002211/WC500132661.pdf. Accessed June 25, 2013.

7. US Food and Drug Administration (FDA). Tudorza Pressair (aclidinium bromide): US prescribing information. Available from: http://www. accessdata.fda.gov/drugsatfda_docs/label/2012/202450s000lbl.pdf. Accessed June 25, 2013.

8. Beeh KM, Singh D, Di SL, Drollmann A. Once-daily NVA237 improves exercise tolerance from the first dose in patients with COPD: the GLOW3 trial. Int J Chron Obstruct Pulmon Dis. 2012;7:503-513. 
9. Chapman KR, Rennard SI, Dogra A, Owen R, Lassen C, Kramer B. Long-term safety and efficacy of indacaterol, a long-acting $\beta_{2}$-agonist, in subjects with COPD: a randomized, placebo-controlled study. Chest. 2011;140(1):68-75.

10. D'Urzo A, Ferguson GT, van Noord JA, et al. Efficacy and safety of once-daily NVA237 in patients with moderate-to-severe COPD: the GLOW1 trial. Respir Res. 2011;12:156.

11. Dahl R, Chung KF, Buhl R, et al. Efficacy of a new once-daily longacting inhaled beta2-agonist indacaterol versus twice-daily formoterol in COPD. Thorax. 2010;65(6):473-479.

12. Donohue JF, Fogarty C, Lötvall J, et al. Once-daily bronchodilators for chronic obstructive pulmonary disease: indacaterol versus tiotropium. Am J Respir Crit Care Med. 2010;182(2):155-162.

13. Kerwin E, Hébert J, Gallagher N, et al. Efficacy and safety of NVA237 versus placebo and tiotropium in patients with COPD: the GLOW2 study. Eur Respir J. 2012;40(5):1106-1114.

14. Kornmann O, Dahl R, Centanni S, et al. Once-daily indacaterol versus twice-daily salmeterol for COPD: a placebo-controlled comparison. Eur Respir J. 2011;37(2):273-279.

15. Korn S, Kerwin E, Atis S, Amos C, Owen R, Lassen C. Indacaterol once-daily provides superior efficacy to salmeterol twice-daily in COPD: a 12-week study. Respir Med. 2011;105(5):719-726.

16. Buhl R, Dunn LJ, Disdier C, et al. Blinded 12-week comparison of once-daily indacaterol and tiotropium in COPD. Eur Respir J. 2011;38(4):797-803.

17. Vogelmeier C, Ramos-Barbon D, Jack D, et al. Indacaterol provides 24-hour bronchodilation in COPD: a placebo-controlled blinded comparison with tiotropium. Respir Res. 2010;11:135.

18. van Noord JA, Aumann JL, Janssens E, et al. Combining tiotropium and salmeterol in COPD: effects on airflow obstruction and symptoms. Respir Med. 2010;104(7):995-1004.

19. Vincken W. An update of bronchodilator treatment of chronic obstructive pulmonary disease (COPD) [abstract]. Ann Respir Med. 2010;1:1-16.

20. Vogelmeier C, Kardos P, Harari S, Gans SJ, Stenglein S, Thirlwell J. Formoterol mono- and combination therapy with tiotropium in patients with COPD: a 6-month study. Respir Med. 2008;102(11):1511-1520.

21. Mahler DA, D’Urzo A, Bateman ED, et al. Concurrent use of indacaterol plus tiotropium in patients with COPD provides superior bronchodilation compared with tiotropium alone: a randomised, double-blind comparison. Thorax. 2012;67(9):781-788.

22. Maltais F, Beck E, Webster D, et al. Four weeks once daily treatment with tiotropium + olodaterol (BI 1744) fixed dose combination compared with tiotropium in COPD patients [abstract]. Eur Respir J. 2010;36:5557.

23. Tashkin DP, Littner M, Andrews CP, Tomlinson L, Rinehart M, DenisMize K. Concomitant treatment with nebulized formoterol and tiotropium in subjects with COPD: a placebo-controlled trial. Respir Med. 2008;102(4):479-487.

24. Tashkin DP, Pearle J, Iezzoni D, Varghese ST. Formoterol and tiotropium compared with tiotropium alone for treatment of COPD. COPD. 2009;6(1):17-25.

25. van Noord JA, Aumann JL, Janssens E, et al. Effects of tiotropium with and without formoterol on airflow obstruction and resting hyperinflation in patients with COPD. Chest. 2006;129(3):509-517.
26. van Noord JA, Aumann JL, Janssens E, et al. Comparison of tiotropium once daily, formoterol twice daily and both combined once daily in patients with COPD. Eur Respir J. 2005;26(2):214-222.

27. Bateman ED, Ferguson GT, Barnes N, et al. Dual bronchodilation with QVA149 versus single bronchodilator therapy: the SHINE study. Eur Respir J. 2013 Dec;42(6):1484-1494.

28. Global Strategy for the Diagnosis, Management and Prevention of COPD, Global Initiative for Chronic Obstructive Lung Disease (GOLD) 2010. Available from: http://www.goldcopd.org/. Accessed November 23, 2013.

29. Clinicaltrials.gov identifier NCT01604278. http://clinicaltrials.gov/ show/NCT01604278. Accessed on 16th January 2014.

30. Mozzicato P. MedDRA. An Overview of the Medical Dictionary for Regulatory Activities. Pharm Med. 2009;23:65-75.

31. Witek TJ Jr, Mahler DA. Minimal important difference of the transition dyspnoea index in a multinational clinical trial. Eur Respir J. 2003;21(2):267-272.

32. Jones PW. St George's Respiratory Questionnaire: MCID. COPD. 2005;2(1):75-79.

33. [No authors listed]. In chronic obstructive pulmonary disease, a combination of ipratropium and albuterol is more effective than either agent alone. An 85-day multicenter trial. COMBIVENT Inhalation Aerosol Study Group. Chest. 1994;105(5):1411-1419.

34. [No authors listed]. Routine nebulized ipratropium and albuterol together are better than either alone in COPD. The COMBIVENT Inhalation Solution Study Group. Chest. 1997;112(6):1514-1521.

35. Mahler DA, Decramer M, D’Urzo A, et al. Dual bronchodilation with QVA149 reduces patient-reported dyspnoea in COPD: BLAZE study. Eur Respir J. October 31, 2013. [Epub ahead of print].

36. Casaburi R, Mahler DA, Jones PW, et al. A long-term evaluation of once-daily inhaled tiotropium in chronic obstructive pulmonary disease. Eur Respir J. 2002;19(2):217-224.

37. Yawn BP, Kaplan A. Co-morbidities in people with COPD: a result of multiple diseases, or multiple manifestations of smoking and reactive inflammation? Prim Care Respir J. 2008;17(4):199-205.

38. Calverley PM, Rennard SI. What have we learned from large drug treatment trials in COPD? Lancet. 2007;370(9589):774-785.

39. Decramer M, Celli B, Kesten S, Lystig T, Mehra S, Tashkin DP. Effect of tiotropium on outcomes in patients with moderate chronic obstructive pulmonary disease (UPLIFT): a prespecified subgroup analysis of a randomised controlled trial. Lancet. 2009;374(9696):1171-1178.

40. Vincken W, van Noord JA, Greefhorst AP, et al. Improved health outcomes in patients with COPD during 1 yr's treatment with tiotropium. Eur Respir J. 2002;19(2):209-216.

41. Vogelmeier C, Bateman E, Pallante J, et al. Efficacy and safety of oncedaily QVA149 compared with twice-daily salmeterol - fluticasone in patients with chronic obstructive pulmonary disease (ILLUMINATE): a randomised, double-blind, parallel group study. Lancet Respir Med. 2013;1(1):51-60.

42. Price D, Yawn B, Brusselle G, Rossi A. Risk-to-benefit ratio of inhaled corticosteroids in patients with COPD. Prim Care Respir J. 2013;22(1): $92-100$. 


\section{Supplementary materials}

Table SI List of study centers

Belgium: UZ Brussel, I0I Avenue de Laerbeek, Brussels 1090; Longartsenpraktijk, 5 Winterslagstraat, Genk 3600; UCL Mont-Godinne, I Avenue Terasse, Yvoir 5530; Saint-Joseph, Sainte-Thérèse, and IMTR, 6 Rue de la Duchère, Gilly 6060; AZ Sint-Elisabeth, I 33 Nederrij, Herentals 2200; Hôpital Erasme, 808 Route de Lennik, Brussels 1070; Centre Hospitalier du Luxembourg, 4 Rue Barblé, Luxembourg 1210; private practice Dr Martinot, 93 Boulevard de la Meuse, Jambes 5100; private practice - Dr Aumann, 36/2A Prins Bisschopssingel, Hasselt 3500; private practice Dr Delobbe, 6A Chemin des quartiers, Malmedy 4960; Centre Hospitalière Universitaire André Vésale, 706 Rue de Gozée, Montigny-le-Tilleul 6100; Centre Hospitalière Universitaire Sart Tilman, Bâtiment B 35 Sart Tilman, Liège 4000; Clinique Notre-Dame De Grâce, 212 Chee de Nivelles, Gosselies 604I; Sint-Elisabeth Ziekenhuis, 166 Rubensstraat, Turnhout 2300

Bulgaria: Medical Centre of Pneumophthisiatric Diseases EOOD, 78 Kiril i Metodii Street, Sofia 1000; MHAT Stara Zagora, II Armeiska Street, 6000 Stara Zagora; SHAT for Pneumophthisiatric Diseases, I Aleya Lilia Street, Ruse 7002; UMHAT Sveti Georgi, 66 Peshtersko Shose Boulevard, Plovdiv 4002; Military Medical Academy - MHAT, 3 Georgi Sofiiski Street, Sofia 1606; UMHAT Dr Georgi Stranski, EAD, 8I Vladimir Vazov Street, Pleven 5800; Multiprofile Hospital for Active Treatment Sveta Marina, I Hristo Smirnenski Street, Varna 90I0; SHATPD St Sofia, 19 Ivan Geshov Boulevard, Sofia |43|

Greece: SOTIRIA General Hospital, 152 Mesogeion Avenue, Athens II527; Papageorgiou General Hospital of Thessaloniki, Periferiaki odos Thessaloniki-Neas Efkarpias, Thessaloniki 56403; General Hospital of Athens Evangelismos, 45-47 Ipsilantou, Athens 10676

Hungary: Ujpesti Egeszsegugyi Szolgaltato, 30 Gorgey Artur Street, Budapest 1046; Csongrad Megye Mellkasi Betegsegek Szakkorhaza, 36 Alkotmany Street, Deszk 6772; Dr Romics Laszlo Egeszsegugyi Intezmeny - Tudogondozo, 40 Hivatalnok Street, Erd H-2030; Tormay Karoly Eu Kozpont Tudobeteg-Gondozo Intezete, 62 Ady Endre Setany, Godollo 2100; Orszagos Koranyi TBC es Pulmonologiai Intezet, I Piheno Street, Budapest II2I

Ireland: Department of Rheumatology, Clinical Investigation Unit, Cork University Hospital, Wilton, Cork

Russia: NA Semashko Regional Clinical Hospital, 190 Rodionova Street, N Novgorod 603 I26; Hospital I3 of Avtozavodsky Region, 5 I Patriotov Street, N Novogorod 6030 I8; RMA of Postgraduate Education of Roszdrav, 5/2-d Botkinsky Drive, Moscow I253I5; Saratov State Medical University of Roszdrav, II 2 Bolshaya Kazachya Street, Saratov 410012

Slovakia: Respiro - Medical, 8 Nemocnicna Street, Kralovsky Chlmec 077 0I; JURMED, Ambulancia Pneumologie a Ftizeologie, 2 Smetanova Street, Kosice 040 0 I; NsP Jakuba, 21 Jakuba Street, Bardejov 085 0I; DAMIZA, 62/30 Cerveneho Kriza Street, Námestovo 0290I; Sukromna Ambulancia PaF, 1737 Pri Zeleznici Street, Liptovsky Hradok 033 0I; Pulmo-Medik, 4I/I656 Janka Krala Street, Bojnice 972 0I; Klinika Funkcnej Diagnostiky, FNsP, 6 Ruzinovska, Bratislava 82606

Spain: Hospital Virgen de la Victoria, Campus Universitario Teatinos, Malaga, Andalusia 29010; CAP Centelles, 7 Plaza del Mestre, Centelles, Catalonia 08540; Hospital Santa Caterina, Parc Hospitalari Martí i Julia, Dr Castany, Salt, Catalonia 17190; Hospital de Sierrallana, Barrio Ganzo, Torrelavega, Cantabria 39300; Fundacion Hospital Jove, Avenida Eduardo de Castro, Gijon, Asturias 33290; Hospital de Merida, Polígono Nueva Ciudad, Mérida, Badajoz 06800; Hospital del Bierzo, 7 Medicos Sin Fronteras, Ponferrada, Castilla y Leon 24400; Hospital de Sant Boi, 13 Bonaventura Calopa, Sant Boi de Llobregat, Catalonia 08830; Hospital de la Santa Creu i Sant Pau, 167 Avenida de Sant Antoni Ma Claret, Barcelona, Catalonia 08025

Turkey: Sibel A Nayci, Mersin University Medical Faculty, Mersin 33079; Serir A Ozkan, Dr Suat Seren Chest Disease and Surgery, Education and Research Hospital, PI Block, 33I Gaziler Caddesi, Yenisehir/lzmir 35I I0; Sule M Akcay, Baskent University Medical Faculty, Sokak 45, 10 Fevzi Cakmak Caddesi, Bahcelievler, Ankara 06490; Hatice Turker, Sureyya Pasa Chest Diseases and Thoracic Surgery Training Hospital, Istanbul 34854; Emel Caglar, Yedikule Gogus Hastaliklari Egitim ve Arastirma Hastanesi, Istanbul 34020; Ahmet H Ilgazli, Kocaeli University Medical Faculty, Kocaeli 4 I 380

United Kingdom: Jerome Kerrane, Layton Medical Centre, 200 Kingscote Drive, Layton, Blackpool FY3 7EN; Anthony Gunstone, Staploe Medical Centre, Brewhouse Lane Soham, Cambridge CB7 5JD; Christopher Strang, Mortimer Surgery, 72 Victoria Road, Mortimer, Reading, RG7 3SQ; Joanna Nash, Southbourne Surgery, 337 Main Road, Southbourne, Emsworth POI0 8JH; Raj Sharma, Sea Road Surgery, 39-4I Sea Road, Bexhill-on-Sea, East Sussex, TN40 IJj; Trevor Gooding, Atherstone Surgery, I Ratcliffe Road, Atherstone, Warwickshire CV9 IEU; lan Orpen, St James Surgery, Northampton Buildings, Bath BAI 2SR; Gavin Durrant, Rowden Medical Partnership, Rowden Hill, Chippenham, Wiltshire SNI5 2SB; Anthony De Soyza, Freeman Hospital, Freeman Road, Newcastle upon Tyne NE7 7DN; Dinesh Saralaya, Bradford Royal Infirmary, Duckworth Lane, Bradford BD9 6RJ; Lindsey Crockett, Peninsula Practice Health Centre, Mill Hoo, Alderton, Suffolk IPI2 3DA; Paul Ainsworth, Sherbourne Medical Centre, 40 Oxford Street, Leamington Spa, Warwickshire CV32 4RA; See Kwok, Barlow Medical Centre, 828 Wilmslow Road, Manchester M20 2RN; lan Jackson, Sheepcot Medical Centre, Sheepcot Lane, Garston, Watford WD25 OEA; Nicky Simler, Hinchingbrooke Hospital NHS Trust, Hinchingbrooke Park, Huntingdon PE29 6NT; Frances Adams, Strensall Medical Centre, Southfields Road, Strensall, Yorkshire YO32 5UA; Mark D Blagden, Avondale Surgery, 3-5 Avondale Road, Chesterfield S40 4TF; Harmesh Moudgil, Princess Royal Hospital, Apley Castle, Telford TFI 6TF; Johann Brandmair, Cobblers Hall Surgery, Carer's Way Burn Lane, Newton Aycliffe DL5 4SE; Rina Miah, Haven Surgery, Burnhope, Durham DH7 0BD 
Table S2 Medications allowed in the GLOW6 study under certain conditions

\begin{tabular}{ll}
\hline Class of medication & $\begin{array}{l}\text { Condition under which medication } \\
\text { is permitted }\end{array}$ \\
\hline SSRIs & $\begin{array}{l}\text { Stable dose for at least } 30 \text { days prior to } \\
\text { the screening visit and during the study; } \\
\text { screening ECG is normal, with no clinical } \\
\text { evidence of prior ECG abnormalities }\end{array}$ \\
& $\begin{array}{l}\text { Stable dose for at least } 30 \text { days prior to } \\
\text { the screening visit and during the study }\end{array}$ \\
Inhaled corticosteroids & Stable dose for at least 30 days prior to \\
& the screening visit \\
Intranasal corticosteroids & Stable dose for at least 5 days prior to \\
the screening visit (except mizolastine or & terfenadine) \\
H, antagonists & Not administered within 48 hours prior \\
to a study visit
\end{tabular}

Abbreviations: ECG, electrocardiogram; SSRIs, selective serotonin reuptake inhibitors.
Table S3 Procedure for handling missing data in the GLOW6 study

\section{Spirometry}

- $\mathrm{FEV}_{1}, \mathrm{FVC}$, and IC measurements within 6 hours of rescue-medication use or within 7 days of systemic corticosteroid use were set to missing. Trough FEV, was defined as the average of the postdose 23 hour 15 minute and the 23 hour 45 minute FEV, values.

The allowable window for these scheduled measurements was 22 hours 45 minutes to 24 hours 15 minutes. Values measured outside of this window were set to missing. If one of the 23 hour 15 minute or 23 hour 45 minute values was missing, the remaining nonmissing value was taken as trough $\mathrm{FEV}_{1}$. If both values were missing, trough $\mathrm{FEV}$, was regarded as missing.

- For the primary analysis, if trough FEV, was missing at visit 8 (week 12) the latest nonmissing predose trough $\mathrm{FEV}_{\text {, }}$ (the mean of 45 and 15 minute predose measurements) from visits 5,6 , or 7 (days 29 , 57,84 ) was carried forward (LOCF). These measurements were required to have been taken before the next dose of study medication.

- Missing values for the analysis of secondary spirometry variables were not imputed.

\section{Rescue-medication use}

- The total number of puffs of rescue medication per day over the 12 weeks was calculated and divided by the total number of days with nonmissing rescue-medication data to derive the mean daily number of puffs of rescue medication taken for the patient. If the number of puffs was missing for part of the day (either morning or evening), then a half day was used in the denominator.

Abbreviations: FEV $_{\text {, }}$ forced expiratory volume in I second; FVC, forced vital capacity; IC, inspiratory capacity; LOCF, last observation carried forward.
International Journal of COPD

\section{Publish your work in this journal}

The International Journal of COPD is an international, peer-reviewed journal of therapeutics and pharmacology focusing on concise rapid reporting of clinical studies and reviews in COPD. Special focus is given to the pathophysiological processes underlying the disease, intervention programs, patient focused education, and self management protocols.

\section{Dovepress}

This journal is indexed on PubMed Central, MedLine and CAS. The manuscript management system is completely online and includes a very quick and fair peer-review system, which is all easy to use. Visit $\mathrm{http}: / /$ www.dovepress.com/testimonials.php to read real quotes from published authors. 